Article

\title{
Cross-Linking of Wheat Bran Arabinoxylan by Fungal Laccases Yields Firm Gels
}

\author{
Sanaz Khalighi *(D), Ralf G. Berger ${ }^{\mathbb{D}}$ and Franziska Ersoy ${ }^{\mathbb{D}}$ \\ Institute of food chemistry, Leibniz University Hannover, Callinstr. 5, 30167 Hannover, Germany; \\ rg.berger@lci.uni-hannover.de (R.G.B.); franziska.ersoy@lci.uni-hannover.de (F.E.) \\ * Correspondence: sanaz.khalighi@lci.uni-hannover.de; Tel.: +49-511-762-17257
}

Received: 26 November 2019; Accepted: 25 December 2019; Published: 30 December 2019

\begin{abstract}
The native extractable arabinoxylans (AX) from wheat bran were cross-linked by the commercial laccase $\mathrm{C}(\mathrm{LccC})$ and self-produced laccases from Funalia trogii (LccFtr) and Pleurotus pulmonarius (LccPpu) $(0.04 \mathrm{U} / \mu \mathrm{g}$ FA, each). Dynamic oscillation measurements of the $6 \% \mathrm{AX}$ gels demonstrated a storage modulus of $9.4 \mathrm{kPa}$ for LccC, $9.8 \mathrm{kPa}$ for LccFtr, and $10.0 \mathrm{kPa}$ for LccPpu. A loss factor $\leq 0.6$ was recorded in the range from 20 to $80 \mathrm{~Hz}$ for all three laccases, and remained constant for four weeks of storage, when LccFtr and LccPpu were used. Arabinoxylan gel characteristics, including high water holding capacity, swelling ratio in saliva, and heat resistance indicated a covalently cross-linked network. Neither the mediator compounds caffeic acid and 2,2'-azino-bis(3-ethylbenzothiazoline-6-sulphonic acid (ABTS), nor citrus pectin, enhanced the elastic properties of the gels. Using laccases as an oxidant provided gels with a solid and stable texture, comparable in firmness to traditional gelatin gels. Thus, AX gels can be presented in the vegan, halal, and kosher food markets. They may also find use in pharmaceutical and other industrial applications.
\end{abstract}

Keywords: arabinoxylan gel; laccase; cross-linking; viscoelastic properties

\section{Introduction}

Among commercial hydrocolloids used in the food industry, gelatin is regarded as special and unique, serving multiple functions with a wide range of applications in various industries [1]. However, vegan, halal, and kosher food markets call for non-animal gels, particularly within Europe, with the emergence of bovine spongiform encephalopathy ("mad cow disease") in the 1980s [2].

Most of the common hydrocolloids lack the chemical functionalities for creating additional network nodes, which are required for forming solid gels. Arabinoxylans (AX), the major non-starch polysaccharides in wheat bran, are a by-product of the commercial wheat milling process [3] and may provide a solution. Wheat bran contains approximately $13 \mathrm{mg} / \mathrm{g}$ ferulic acids and up to $50 \%$ non-digestible fibre, mostly AX [4]. These hemicelluloses consist of $\beta-1,4-\mathrm{D}$-xylopyranose decorated with $\alpha$-1,2- and/or $\alpha-1,3-\mathrm{L}$-arabinofuranosyl units. Some of the arabinose residues are ester linked on (O)-5 to FA resulting in ferulated AXs [5,6]. Diferulic (di-FA) and triferulic acids (tri-FA) were identified as covalently cross-linked structures in gelled AX [7,8]. Figure 1 illustrates this oxidative reaction [9]. Besides, AX gels may form in the strong acidic range ( $\mathrm{pH}$ 2) without addition of a cross-linking agent, and at low sugar levels through hydrogen bonds and hydrophobic interactions [10].

As wheat bran is an abundant industrial by-product generated during milling, it may be considered to be a convenient source of AX, which after cross-linking, may serve as a solid vegan gel [11]. The higher the number of ferulic acid moieties on the polysaccharide backbone, the more covalent cross-links may be generated [9]. AX are generally extracted by hot water and/or aqueous alkali and can be fractionated according to their solubility in different solvents, such as water/ethanol mixtures [12]. The incubation time, concentration of alkaline extracted solution and initial mass of wheat bran has a direct 
impact on the number of ferulic acids remaining for cross-linking [13,14]. A recent research on ferulic acid extraction on the laboratory scale indicated that the more wheat bran was used the less ferulic acid was extracted [14]. According to own analyses, little ferulic acid is left in commercial AX, which indicates high $\mathrm{pH}$ and/or long extraction times.

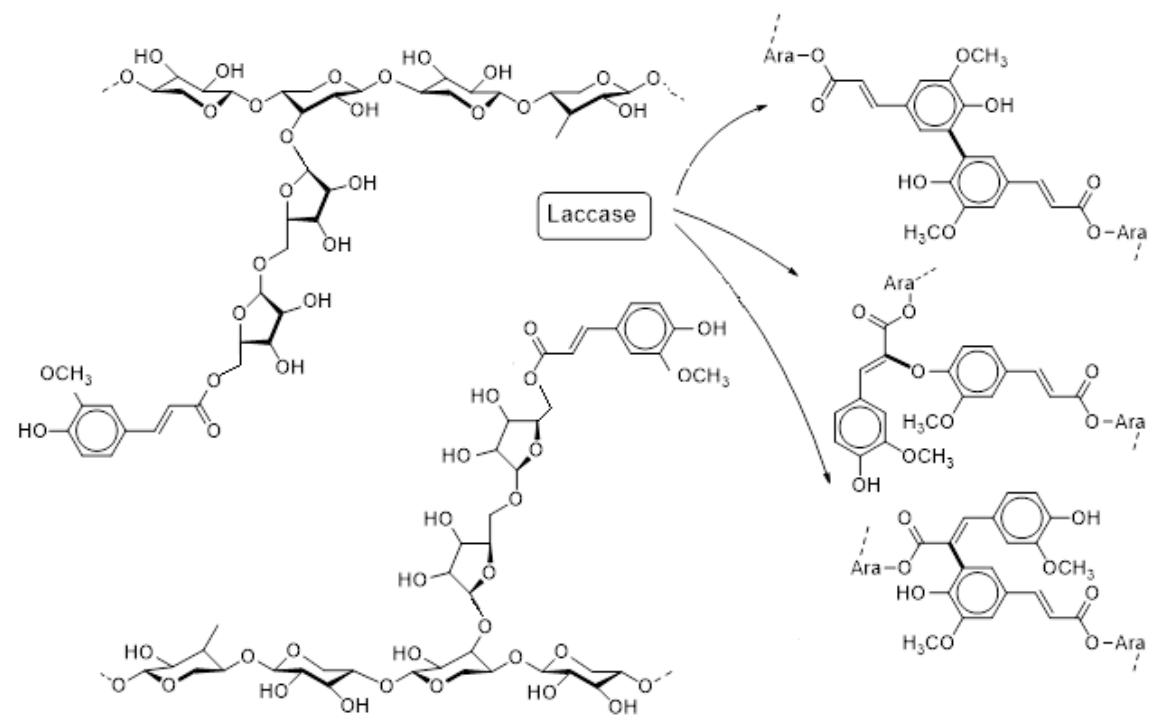

Figure 1. Oxidative gelation as catalyzed by laccases (simplified): Feruloylated arabinoxylan in solution (left) and formation of network knots to constitute a gel (right); $\beta$-1,4-D-Xylopyranose backbone with $\alpha-1,3$-L-arabinofuranosyl side chains carrying feruloyl substituents. Dimerization of adjacent feruloyl moieties occurs through intermediate carbon or oxygen centered radicals.

Various oxidative agents were applied for the cross-linking of AX gels, including hydrogen peroxide, manganese peroxidases, and laccases $[9,15]$. Recent work compared laccase and peroxidase cross-linking activities and concluded that laccases would be preferable for AX gels [16]. Laccases are part of a large group of multi-copper oxidases acting on polyphenols, methoxy-substituted phenols, aromatic diamines, and a range of other compounds [17]. They were suggested as processing aids for wine, beer, and bakery products, and for improving sensory parameters of food [18-20]. Laccase catalysis occurs by reduction of oxygen to water accompanied by the oxidation of the substrate. The ability of laccase $C$ to enhance the cross-linking in skimmed milk yogurt was shown before [21].

The objective of this study was to extract genuine AX from wheat bran with as many ferulic acid moieties still bound to the hemicellulose backbone as possible. The working hypothesis was that such a native substrate, in contrast to commercial $\mathrm{AX}$, may be converted by laccases to plant-based gels with a firmness similar to traditional gelatin gels.

\section{Materials and Methods}

\subsection{Materials}

Wheat bran was bought from Alnatura GmbH (Darmstadt, Germany). All chemicals were obtained from Carl Roth (Karlsruhe, Germany), Fluka (Buchs, Switzerland), and Sigma-Aldrich (Taufkirchen, Germany).

\subsection{Enzymes}

The commercial laccase C (EC 1.10.3.2), purified from a Trametes species, was purchased from ASA Spezialenzyme (Wolfenbüttel, Germany). The xylanase side-activity of the laccase $C$ was determined using the 3,5-dinitrosalicylic acid (DNSA) test [22]. Based on previous work [21,23], laccases were also purified from the basidiomycetes Funalia trogii (DSMZ 11919) and Pleurotus pulmonarius (DSMZ 
5331). To obtain laccase Ftr from Funalia trogii, the fungus was cultivated in SNL medium [21] and incubated at $25^{\circ} \mathrm{C}$ and $180 \mathrm{rpm}$ for three weeks. The purification was done by hydrophobic interaction chromatography on phenyl FF column and ion exchange chromatography on Q-sepharose $\mathrm{XL}$ material [24]. The activity of the extracted and purified enzyme was $2.3 \times 10^{5} \mathrm{U} / \mathrm{L}$. Laccase activity was measured at $25^{\circ} \mathrm{C}$ and $\mathrm{pH} 4.5$ using the 2,2' -azino-bis(3-ethylbenzothiazoline-6-sulphonic acid) (ABTS) assay [21].

Laccase Ppu was isolated from a recombinant Pichia pastoris with a laccase gene from the fungus Pleurotus pulmonarius cultivated on BMM medium [23]. Pichia pastoris was incubated at $25^{\circ} \mathrm{C}$ and $180 \mathrm{rpm}$ for one week. Purification of the laccase Ppu was achieved by Agarose Ni-NTA column [22]. The activity of the purified enzyme was $1.92 \times 10^{5} \mathrm{U} / \mathrm{L}$.

\subsection{General Experimental Setup}

All data presented are averages of duplicate measurements. The standard deviation of replicates for the rheological measurements was typically below $5 \%$.

\subsection{Wheat Bran Arabinoxylan Extraction}

Wheat bran was manually milled to a 14-mesh particle size using liquid nitrogen. One hundred gram were suspended in $500 \mathrm{~mL}$ ethanol at $25{ }^{\circ} \mathrm{C}$ and $250 \mathrm{rpm}$ overnight to eliminate lipophilic components. After filtration, the wheat bran was boiled in $700 \mathrm{~mL}$ water for $30 \mathrm{~min}$ to gelatinize starch and inactivate enzymes before centrifugation at $12,000 \times \mathrm{g}$ for $10 \mathrm{~min}$ at $20^{\circ} \mathrm{C}$ (centrifuge $460 \mathrm{R}$ Hettich Rotanta, Taufkirchen, Germany). Afterwards, it was treated with $500 \mathrm{~mL} \mathrm{NaOH}(0.5 \mathrm{~mol} / \mathrm{L})$ at $40{ }^{\circ} \mathrm{C}, 180 \mathrm{rpm}$ for $40 \mathrm{~min}$ in the dark. Residual bran was removed by centrifugation $(12,000 \times \mathrm{g}$, $10 \mathrm{~min}$ and $\left.20^{\circ} \mathrm{C}\right)$. The supernatant was acidified to $\mathrm{pH} 4.5$ with $\mathrm{HCl}(3 \mathrm{~mol} / \mathrm{L})$ and then centrifuged at $12,000 \times g$ and $20^{\circ} \mathrm{C}$ for $15 \mathrm{~min}$. The recovered supernatant was precipitated in ethanol at $4{ }^{\circ} \mathrm{C}$ overnight, freeze-dried, and milled [13]. The bound ferulic acid content was determined by incubating $2 \mathrm{~mL}$ of $10 \%$ AX solution with $2 \mathrm{~mL} \mathrm{KOH} / \mathrm{NaOH}\left(1: 1 ; 4 \mathrm{~mol} / \mathrm{L}\right.$ each) at $50{ }^{\circ} \mathrm{C}$ and $220 \mathrm{rpm}$ for $4 \mathrm{~h}$. The reaction was stopped with $1 \mathrm{~mL} 60 \%$ acetic acid and $5 \mathrm{~mL}$ methanol. After centrifugation at $15,000 \times g$ and $4{ }^{\circ} \mathrm{C}$ for $15 \mathrm{~min}$, ferulic acid (FA) was analyzed by HPLC at $\lambda=323 \mathrm{~nm}$ (SPD-10A VP, Shimadzu Deutschland GmbH, Berlin, Germany) [25].

\subsection{Wheat Bran Arabinoxylan Cross-Linking}

To cross link arabinoxylan gel, $6 \%(w / v)$ wheat bran AX solution in $0.05 \mathrm{M}$ citrate phosphate buffer $\mathrm{pH} 5.5$ was incubated with different laccases $(0.04 \mathrm{U} / \mu \mathrm{g} \mathrm{FA}, \mathrm{LccC}, \mathrm{LccFtr}$, and LccPpu) overnight without shaking. The impact of caffeic acid ((E)-3-(3,4-dihydroxyphenyl)-2-propenoic acid) and ABTS $(1,3$, and $5 \mathrm{mM})$ as mediators and citrus peel pectin $(1$ and $3 \%(w / v))$ instead of AX were likewise investigated. Commercial wheat bran AX (Megazyme, Bray, Ireland) without ferulic acid was used as negative control.

\subsection{Rheology}

To carry out rheological measurements, a Physica MCR 301 rheometer (Anton Paar, Graz, Austria) with plate geometry (25 mm diameter) and a gap width of $1 \mathrm{~mm}$ was used. Oscillation experiments ( $\gamma=0.01 \%$ to $100 \%$ ) were performed at a constant frequency of $\omega=10 \mathrm{rad} / \mathrm{s}$ to ascertain the linear viscoelastic region (LVE) [26]. Frequency sweep test used a frequency of 0.01 to $100 \mathrm{~Hz}$ with an applied strain of $5 \%$. All tests were carried out at $25^{\circ} \mathrm{C}$ in duplicates. Rheoplus software was used to calculate storage modulus $\left(G^{\prime}\right)$, loss modulus $\left(G^{\prime \prime}\right)$, and loss factor $\tan \delta\left(=G^{\prime \prime} / G^{\prime}\right)$.

Rheological properties of gel samples were analyzed weekly over six weeks of storage at $25^{\circ} \mathrm{C}$. Injection of one unit xylanase activity into the gel and incubation at $30^{\circ} \mathrm{C}$ for $2 \mathrm{~h}$ destroyed the structure of the gels and facilitated the ABTS assay to estimate the residual laccase activity during storage. Viscoelastic properties of the AX gels were compared with $6 \%$ gelatin gels (Dr. Oetker GmbH, Bielefeld, Germany) prepared with the same buffer, but without any other additives. 


\subsection{Analysing Diferulic Acids in Arabinoxylan Gels}

\subsubsection{Sample Preparation}

Arabinoxylan gel (cross-linked with LccPpu) was enzymatically hydrolysed with a xylanase: ferulic acid esterase (1:1) mix for $3 \mathrm{~h}$ at $40{ }^{\circ} \mathrm{C}, \mathrm{pH} 6$ and $220 \mathrm{rpm}$. Xylanase from Trichoderma viride was purchased from Fluka (Buchs, Switzerland). The recombinant ferulic acid esterase originated from Streptomyces werraensis [27]. The hydrolysed sample was purified on $20 \mathrm{~mL}$ XAD 2 resin column as described by Malunga and Beta (2016) [28]. Adsorbed diferulic acids were eluted in $30 \mathrm{~mL}$ methanol:formic acid (9:1), concentrated under a nitrogen stream, lyophilised, and dissolved in $50 \mu \mathrm{L}$ acetonitrile.

\subsubsection{High Performance Liquid Chromatography Mass Spectrometry}

To detect cross-linked diferulic acids in the gel, $15 \mu \mathrm{L}$ hydrolysate was loaded on a Varian 1200 LCMS (Agilent, Santa Clara, CA, USA) equipped with a C18 Pyramid column (Macherey-Nagel, Düren, Germany). As eluent A, water with $0.1 \%$ formic acid was used, whereas acetonitrile with $0.1 \%$ formic acid was applied as eluent $B$. A separation was achieved using a stepwise gradient at a flow velocity of $0.1 \mathrm{~mL} / \mathrm{min}$ : sample loaded in $10 \%$ eluent B, followed by 10 to $100 \%$ eluent $\mathrm{B}$ in $20 \mathrm{~min}, 100 \%$ eluent B for $10 \mathrm{~min}, 100$ to $10 \%$ in $5 \mathrm{~min}$ and ended with $10 \%$ eluent B for $3 \mathrm{~min}$. Mass analysis was performed as follows: Needle voltage $( \pm) 5000 /-4500 \mathrm{~V}$; spray shield voltage $( \pm) 600 /-600 \mathrm{~V}$; spray chamber temperature $50^{\circ} \mathrm{C}$; drying gas temperature $350{ }^{\circ} \mathrm{C}$; nebulizing gas pressure $379 \mathrm{kPa}$; drying gas pressure $124 \mathrm{kPa}$, and capillary voltage $( \pm)$ 40/-40 V. Mass spectrometry analysis was conducted in a scanning range from 100 to $800 \mathrm{~m} / \mathrm{z}$ for $50 \mathrm{~min}$. In the MS/MS experiments, $10 \mathrm{eV}$ collision energy was chosen to fragment the molecules.

\subsection{Melting Point}

Mechanical spectra of AX (gels formed with LccPpu) and gelatin gel (6\%) were recorded using a Physica MCR 301 rheometer with plate geometry $25 \mathrm{~mm}$ diameter and a gap width of $1 \mathrm{~mm}$. The measurement was performed at a temperature rate of $10^{\circ} \mathrm{C} / \mathrm{min}$, angular frequency $10 \mathrm{1} / \mathrm{s}$ and strain $0.5 \%$, during heating from 20 to $100{ }^{\circ} \mathrm{C}$ for the $\mathrm{AX}$ gel and 5 to $42^{\circ} \mathrm{C}$ for the gelatin gel. Mechanical parameters were recorded every $0.1 \mathrm{~min}$.

\subsection{Water Holding Capacity (WHC)}

To conduct the WHC test, $1 \mathrm{~g}$ gel sample $(6 \%)$ was centrifuged at $700 \times g$ for $30 \mathrm{~min}$ at $10{ }^{\circ} \mathrm{C}$. The water holding capacity was calculated as [29]:

$$
\text { WHC }(\%)=(\text { mass of gel after centrifugation } / \text { mass of gel sample }) \times 100
$$

\subsection{Swelling Ratio}

Arabinoxylan (gels formed with LccPpu) and gelatin gel (6\%) with a defined volume were immersed in artificial saliva composed as described in Amal et al. (2015) [30] for $10 \mathrm{~min}$ at room temperature. The gel volume was measured every two minutes and the swelling ratio calculated as:

$$
\text { Swelling ratio }=\mathrm{V}_{\mathrm{n}} / \mathrm{V}_{0}
$$

where $V_{n}$ is the volume of the gels after every two minutes immersion $\left(\mathrm{m}^{3}\right)$ and $V_{0}$ is the initial volume of the gel before immersion in artificial saliva $\left(\mathrm{m}^{3}\right)$. 


\section{Results}

\subsection{Wheat Bran Arabinoxylan Gel Characterization}

\subsubsection{Wheat Bran Arabinoxylan}

The yield of the extracted AX was $2.8 \%$ (mass of AX/mass of wheat bran) and contained $2.17 \pm$ $0.06 \mu \mathrm{g}$ ferulic acid/mg AX. Intact ferulic acid in the extracted arabinoxylan was cross-linked with laccase Ftr and Ppu to form a hard gel.

\subsubsection{Oscillatory Tests on Gels from Self-Extracted and Commercial AX Formed Using LccC}

During a sweep test, the amplitude of the deformation was varied ( $\gamma=0.01 \%$ to $100 \%$ ), while the frequency was kept constant $(\omega=10 \mathrm{rad} / \mathrm{s})$. For the analyses, the storage modulus $\mathrm{G}^{\prime}$ and the loss modulus $\mathrm{G}^{\prime \prime}$ were plotted against the deformation $(\gamma)$. Gels from self-extracted and commercial AX (as negative control) had constant $G^{\prime}$ and $G^{\prime \prime}$ at $0.1 \leq \gamma \leq 70 \%$, which showed that the sample structures were undisturbed. In the negative control, $G^{\prime \prime}$ was $>G^{\prime}$, while in the $A X$ gels $G^{\prime}$ was $>G^{\prime \prime}$.

Viscoelastic properties derived from a frequency sweep test at $\omega=10 \mathrm{rad} / \mathrm{s}$ presented $\mathrm{G}^{\prime}=9.35 \pm$ 0.017 and $6 \pm 0.018 \mathrm{kPa}$ and $\mathrm{G}^{\prime \prime}=2.45 \pm 0.024$ and $8.03 \pm 0.021 \mathrm{kPa}$ for AX gels $(6 \%)$ and the negative control $(6 \%)$, respectively. The loss factors of $\mathrm{AX}$ gels and the negative control formed using laccase $\mathrm{C}$ were $\tan \delta \leq 0.8$ and $\tan \delta \geq 1$, respectively.

\subsubsection{Different Laccases from Basidiomycetes}

Basidiomycete fungi are well known for their high-redox potential laccases. A possibly different effect of laccases from Pleurotus pulmonarius (Ppu) and Funalia trogii (Ftr) on the rheological properties of $6 \%$ AX gels compared with the action of commercial laccase $C$ was investigated. The gels obtained using laccase Ftr and Ppu had a large linear viscoelastic region at $0.1 \leq \gamma \leq 70 \%$ (data not shown). The viscoelastic properties deduced from a frequency sweep test at $\omega=10 \mathrm{rad} / \mathrm{s}$ are shown in Table 1 . The loss factors of the 6\% AX gels formed by the different laccases can be found in Figure 2. Gels formed by laccase Ppu and Ftr possessed higher storage moduli and lower loss factors in comparison with laccase $C$. The xylanase activity in laccase $C$ was determined by the DNSA test [31]. The used technical preparation contained $1.9 \mathrm{U} / \mathrm{mg}$ xylanase activity.

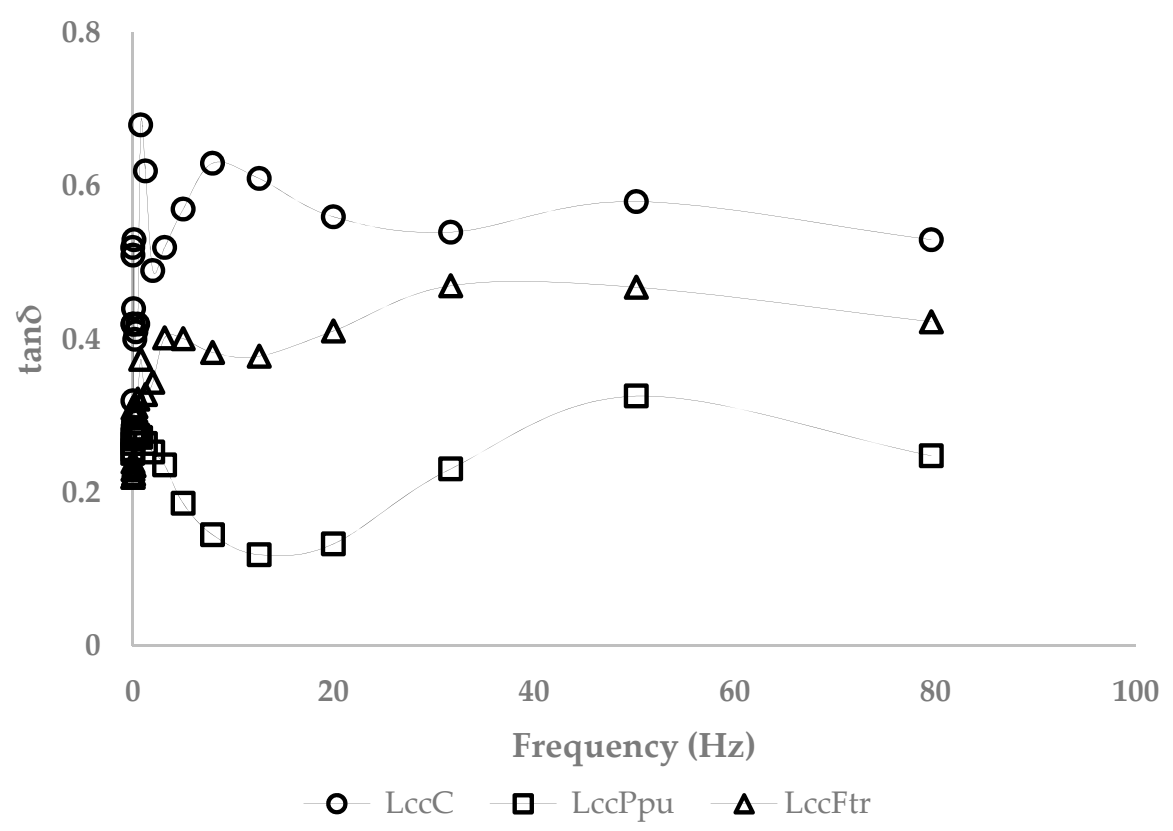

Figure 2. Loss factor of the arabinoxylan gels (6\%), formed with laccase C (circles), Ppu (squares), and Ftr (triangles). 
Table 1. Viscoelastic properties of the $6 \%$ arabinoxylan gels formed with different laccases.

\begin{tabular}{ccc}
\hline Arabinoxylan Gel 6\% & \multicolumn{2}{c}{ Viscoelastic Properties } \\
\hline & $\mathrm{G}^{\prime}(\mathrm{kPa})$ & $\mathrm{G}^{\prime \prime}(\mathrm{kPa})$ \\
\hline $\mathrm{LccC}$ & 9.3 & 2.4 \\
$\mathrm{LccPpu}$ & 10 & 2.2 \\
$\mathrm{LccFtr}$ & 9.8 & 2.5 \\
\hline \multicolumn{3}{c}{$\mathrm{SD} \leq 0.03 \mathrm{kPa}}$.
\end{tabular}

\subsubsection{Effect of Citrus Pectin and Mediators on Arabinoxylan Gels}

Different additives were tried to enhance the firmness of the AX gels. Table 2 indicates the storage modulus, loss modulus, and loss factor of the gels formed in the presence of the reaction mediators caffeic acid (CA), ABTS, or citrus pectin.

Table 2. Viscoelastic properties of $6 \%$ Arabinoxylans (AX) gels, storage modulus $\mathrm{G}^{\prime}(\mathrm{kPa})$, and loss modulus $\mathrm{G}^{\prime \prime}(\mathrm{kPa})$.

\begin{tabular}{|c|c|c|c|c|c|c|c|c|c|c|c|c|c|c|c|c|}
\hline \multirow{3}{*}{ AX Gel 6\% } & \multicolumn{12}{|c|}{ Mediators } & \multicolumn{4}{|c|}{ Pectin C } \\
\hline & \multicolumn{2}{|c|}{$1 \mathrm{mMCA}^{\mathrm{a}}$} & \multicolumn{2}{|c|}{$3 \mathrm{mM} \mathrm{CA}$} & \multicolumn{2}{|c|}{$5 \mathrm{mM}$ CA } & \multicolumn{2}{|c|}{$\begin{array}{c}1 \mathrm{mM} \\
\text { ABTS }^{\mathrm{b}}\end{array}$} & \multicolumn{2}{|c|}{$\begin{array}{l}3 \mathrm{mM} \\
\text { ABTS }\end{array}$} & \multicolumn{2}{|c|}{$\begin{array}{l}5 \mathrm{mM} \\
\text { ABTS }\end{array}$} & \multicolumn{2}{|c|}{$1 \%$} & \multicolumn{2}{|c|}{$3 \%$} \\
\hline & $\mathrm{G}^{\prime}$ & $\mathrm{G}^{\prime \prime}$ & $\mathrm{G}^{\prime}$ & $\mathrm{G}^{\prime \prime}$ & $\mathrm{G}^{\prime}$ & $\mathrm{G}^{\prime \prime}$ & $\mathrm{G}^{\prime}$ & $\mathrm{G}^{\prime \prime}$ & $\mathrm{G}^{\prime}$ & $\mathrm{G}^{\prime \prime}$ & $\mathrm{G}^{\prime}$ & $\mathrm{G}^{\prime \prime}$ & $\mathrm{G}^{\prime}$ & $\mathrm{G}^{\prime \prime}$ & $\mathrm{G}^{\prime}$ & $\mathrm{G}^{\prime \prime}$ \\
\hline $\mathrm{LccC}$ & 8.1 & 2.7 & 4.5 & 1.1 & 3.5 & 1 & 8.8 & 2.4 & 9.3 & 2 & 6.4 & 2.3 & 9.1 & 2.1 & 9.4 & 1.9 \\
\hline LccPpu & 8.5 & 2.1 & 4.6 & 1.1 & 3.6 & 1 & 9.2 & 2.1 & 9.3 & 2.3 & 6.9 & 2.2 & 9.1 & 2.1 & 9.4 & 2.3 \\
\hline LccFtr & 8.4 & 2.1 & 4.6 & 1.4 & 3.5 & 1.1 & 9.1 & 2.2 & 9 & 2.1 & 6.8 & 2.2 & 9.1 & 2.2 & 9.4 & 2.4 \\
\hline
\end{tabular}

Caffeic acid, especially at concentrations of 3 and $5 \mathrm{mM}$, decreased the storage moduli of the gels and had a destructive effect on the final gel structure. Analysing loss factors of the gels showed much higher values than without CA or just $1 \mathrm{mM}$ of the mediator, and the same was true for the viscosity.

Likewise, the non-food mediator ABTS significantly affected the viscoelastic properties of AX gels. Increasing the concentration of ABTS up to $5 \mathrm{mM}$ resulted in lower storage moduli and higher loss factors of the gels in comparison with $3 \mathrm{mM}$ ABTS. In addition, the loss factor of the gels formed with $3 \mathrm{mM}$ ABTS was lower than 0.6 indicating elastic gels.

One and three percent pectin $C$ were added to improve the viscoelastic properties, but no increase in storage modulus was observed. The rheological examination of the AX gels with pectin indicated that the storage moduli in the presence of $3 \%$ pectin were higher than in $1 \%$ samples, and their loss factor was $<0.5$. As can be inferred from Tables 1 and 2, mediators and pectin $C$ did not improve the storage and loss moduli and loss factors of AX gels.

\subsection{Storage Stability of Arabinoxylan Gels}

The storage stability of the enzymatically cross-linked AX gels $(6 \%)$ was investigated over six weeks at $25^{\circ} \mathrm{C}$. Besides, the residual activity of the laccases Ppu, Ftr, and $\mathrm{C}$ was determined. The storage modulus of the AX gels with laccase C showed a substantial decrease from 9.35 to $2.65 \mathrm{kPa}$ after two weeks of storage. The storage moduli of the AX gels with laccase Ppu and Ftr are shown in Figure 3 over 42 days of storage. Gels formed with laccase Ftr showed a decreasing $\mathrm{G}^{\prime}$ after 28 days. By the end of day 35, the storage modulus reached around $6.32 \mathrm{kPa}$ and lost its viscoelastic properties as reflected by a high loss modulus of $8.45 \mathrm{kPa}\left(\mathrm{G}^{\prime \prime}>\mathrm{G}^{\prime}\right)$. AX gels formed with LccFtr reached a loss factor of 4.23 on day 42.

Gels formed using laccase Ppu showed a $\tan \delta \leq 0.5$ after 28 days of storage. Although an increase in loss factor was observed after day $35(\tan \delta \leq 0.9)$, the storage modulus remained constant (Figure 3$)$. 


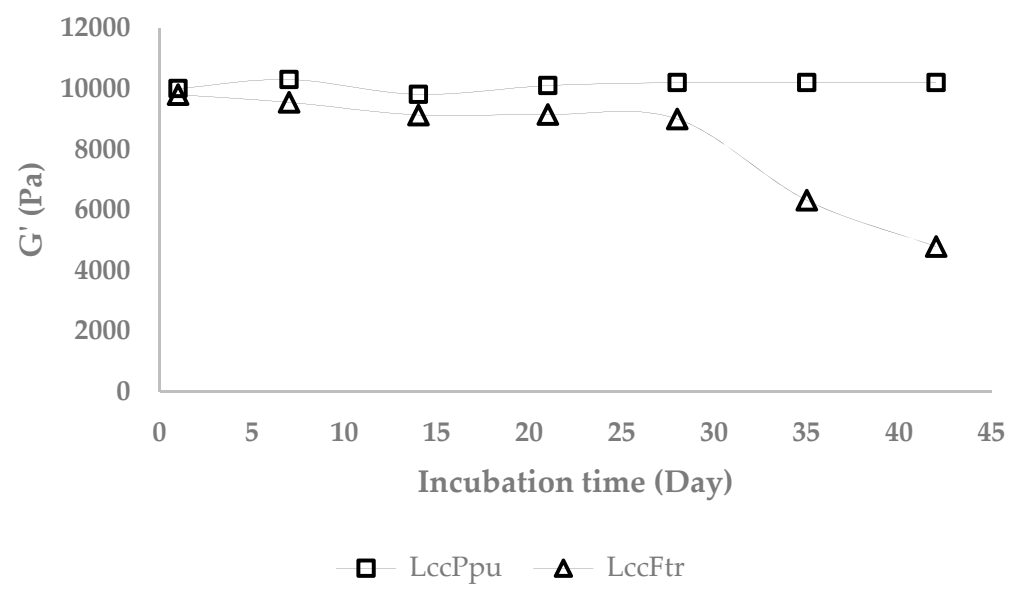

Figure 3. Storage modulus of the arabinoxylan (AX) gels $(6 \%)$ during six weeks incubation at $25^{\circ} \mathrm{C}$.

The activity of residual laccases during the incubation at $25^{\circ} \mathrm{C}$ was determined using the ABTS assay (Figure 4). The activity of the laccase Ppu slightly declined from 0.04 to $0.0224 \mathrm{U} / \mu \mathrm{g}$ FA, whereas the activity of laccase Ftr strongly decreased to $0.0033 \mathrm{U} / \mu \mathrm{g}$ FA. An inverse correlation was observed between the activity of the residual laccases and the loss factor of the gels. A slight decrease in activity of residual laccase Ppu resulted in a gentle increase of the loss factor from 0.5 to $\leq 0.9$ during storage. The reduction of the residual laccase Ftr activity was accompanied by a distinct rise of the loss factor from 0.47 to 4.23 from day 28 to 42 .

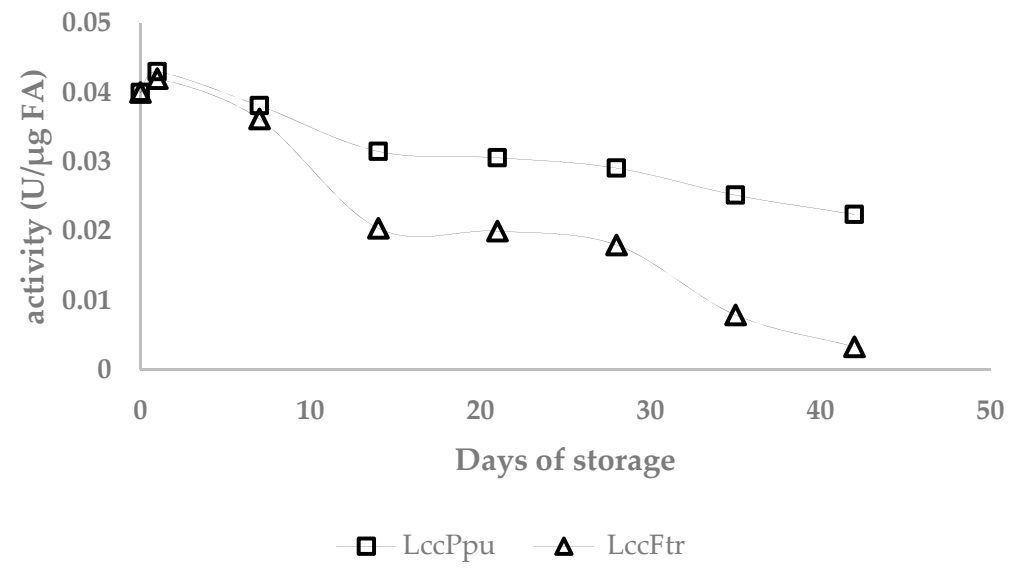

Figure 4. Activity of residual laccases in the AX gels during incubation at $25^{\circ} \mathrm{C}$.

\subsection{Comparison of the Viscoelastic Properties of AX and Gelatin Gels}

The viscoelastic properties of AX $(6 \%)$ and gelatin gels $(6 \%)$ were analyzed by a frequency sweep test at $\omega=10 \mathrm{rad} / \mathrm{s}$ (Figure 5). Storage and loss modulus of the gelatin gel were 9.75 and $2.24 \mathrm{kPa}$, respectively; the loss factor was $<0.3$. At frequencies lower than $50 \mathrm{~Hz}$, the loss factors of $6 \% \mathrm{AX}$ gels formed using laccase Ppu were slightly higher than for gelatin gels. This difference was more significant with laccase Ftr, which obtained loss factors $<0.5$. The storage moduli of AX gels and gelatin were on the same level (data not shown). They all showed loss factors $<1$, which confirmed their elastic properties.

\subsection{Identifying Diferulic Acids in Cross-Linked Arabinoxylan Gel}

The oxidative gelation of $\mathrm{AX}$ was supposed to result from the dimerization of FA residues on the polysaccharide chains. The FA dimerization mechanism starts with an abstraction of an $\mathrm{H}$ atom of the $\mathrm{OH}$ group at the ring position of FA leading to a phenoxy radical. Then, this radical is stabilized by resonance along the aromatic ring (C-4/C-5) and the double bound (C-8) of the side chain. Subsequently, 
two phenoxy or alkoxy radicals cross-link and the coupling of unpaired electrons of two radicals forms a new covalent bond that connects two arabinoxylan chains. Consequently, the structure of the dimers formed during gelation depends on the radical position [32] (Figure 1). Liquid chromatography mass spectrometry (LCMS) showed a peak (retention time about $14 \mathrm{~min}$ ) with $\mathrm{m} / \mathrm{z} 387(+)$, indicative of a diferulic acid (Figure 6, peak A) [33]. An MS/MS fragmentation experiment on this peak led to fragment ion masses m/z 369 (- $\left.\mathrm{H}_{2} \mathrm{O}\right), 343$ (-COO-), 327 (- $\left.\mathrm{CH}_{3} \mathrm{COOH}\right), 263$ (-hydroxy, methoxy-phenyl-), 193 (-feruloyl-), and 149 (-vinyl-guaiacyl-), which fit to 8-O-4' diferulic acid (Figures 6A and 7). Moreover, a big peak at a retention time of about $11 \mathrm{~min}$ was observed with $\mathrm{m} / \mathrm{z} 386.6$ and 387.1 ions (Figure 6, peak B).

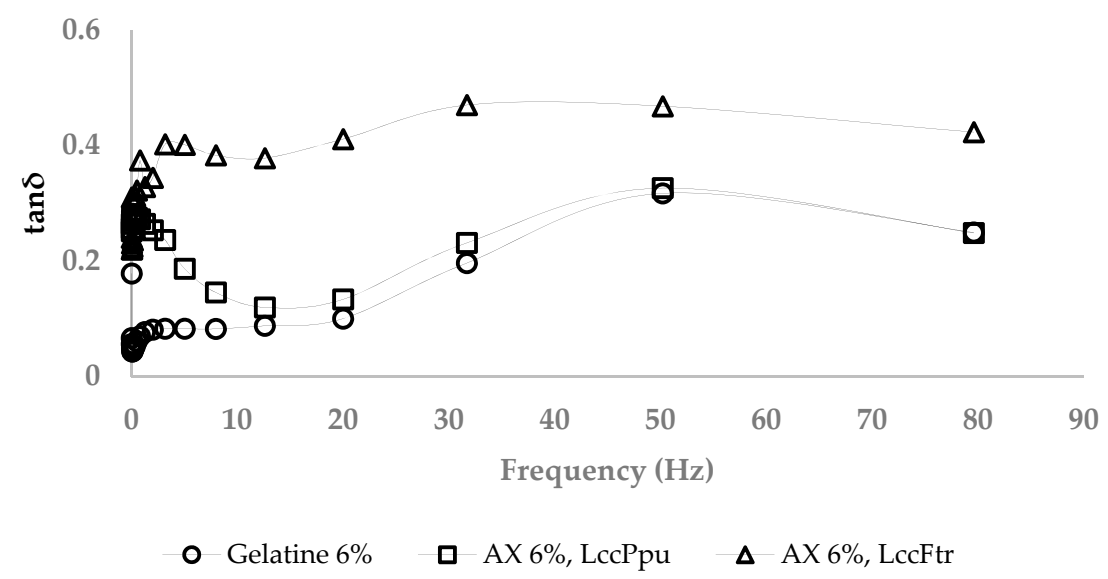

Figure 5. Comparing loss factors of $\mathrm{AX}(6 \%)$ and gelatin gels $(6 \%)$.

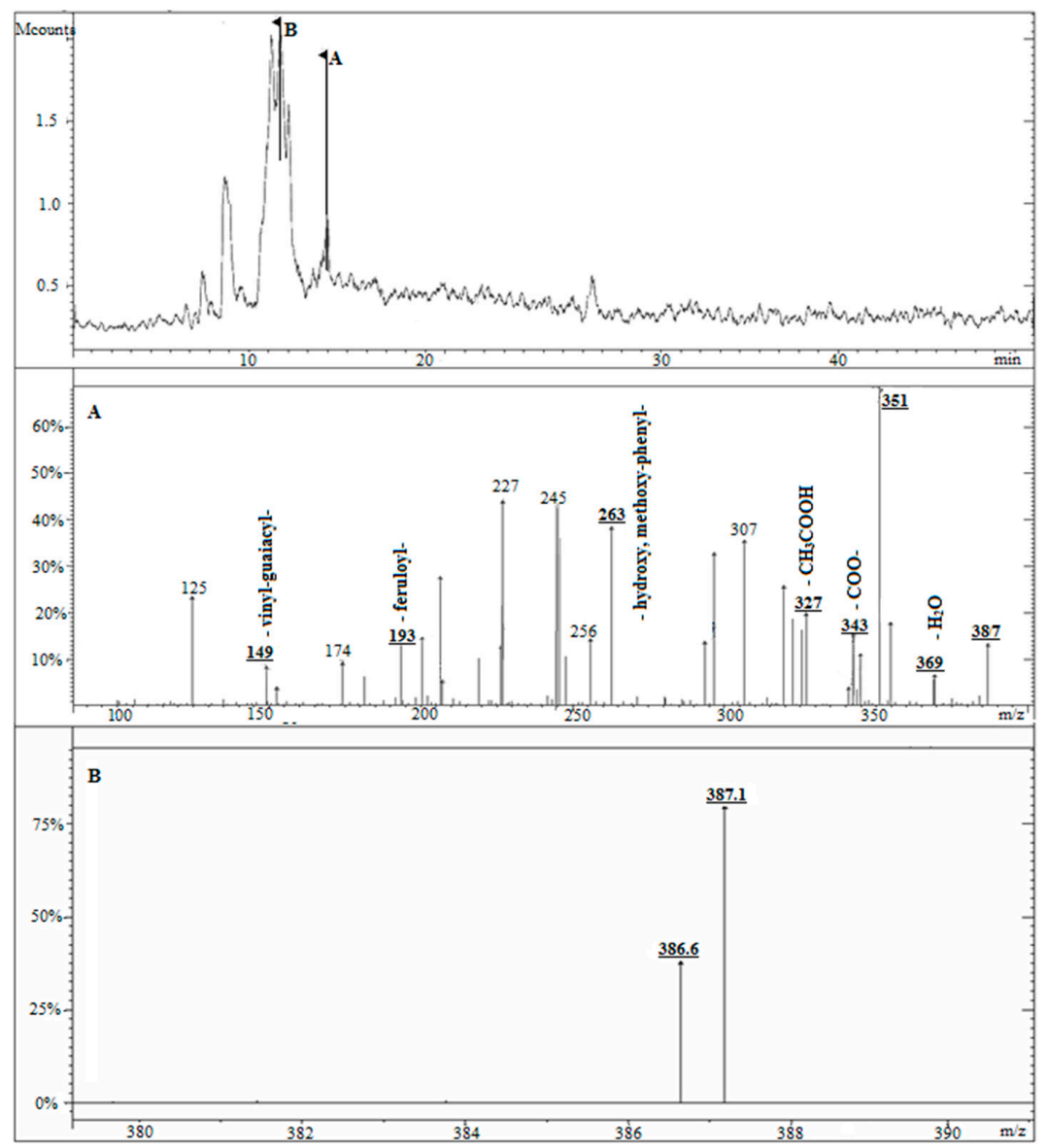

Figure 6. Liquid chromatography mass spectrometry (LCMS) and MS/MS spectra of diferulic compounds in arabinoxylan gel. (A) MS fragmentations of peak A. (B) MS fragmentations of peak B. 
<smiles>COc1cc(C=CC(=O)Oc2ccc(C=CC(=O)O)cc2OC)ccc1O</smiles>

Figure 7. Molecular structure of 8-O-4 diferulic acid with MS/MS fragmentation sites.

\subsection{Melting Point}

The melting point of AX (formed with LccPpu) and gelatin gels was measured by a constant frequency oscillatory test. Figures 8 and 9 present the temperature dependence of dynamic modulus $\left(G^{\prime}\right.$ and $\left.G^{\prime \prime}\right)$ during isochronal temperature sweeps in heating from 5 to $42{ }^{\circ} \mathrm{C}$ and 20 to $100{ }^{\circ} \mathrm{C}$ for gelatin and AX gels, respectively. The starting temperature was chosen according to the gel formation temperature. Gelatin gel showed a high storage modulus during heating from 5 to almost $30{ }^{\circ} \mathrm{C}$ followed by a sudden drop at around $32^{\circ} \mathrm{C}$. The melting point of gelatin depends on its grade and concentration, but is typically $\leq 35^{\circ} \mathrm{C}$ [26]. As shown in Figure 9, there was a gradual decrease of the storage modulus with increasing temperatures in AX gels, which presented a linear correlation between rising temperature and falling storage modulus with $\mathrm{R}^{2}=0.96$.

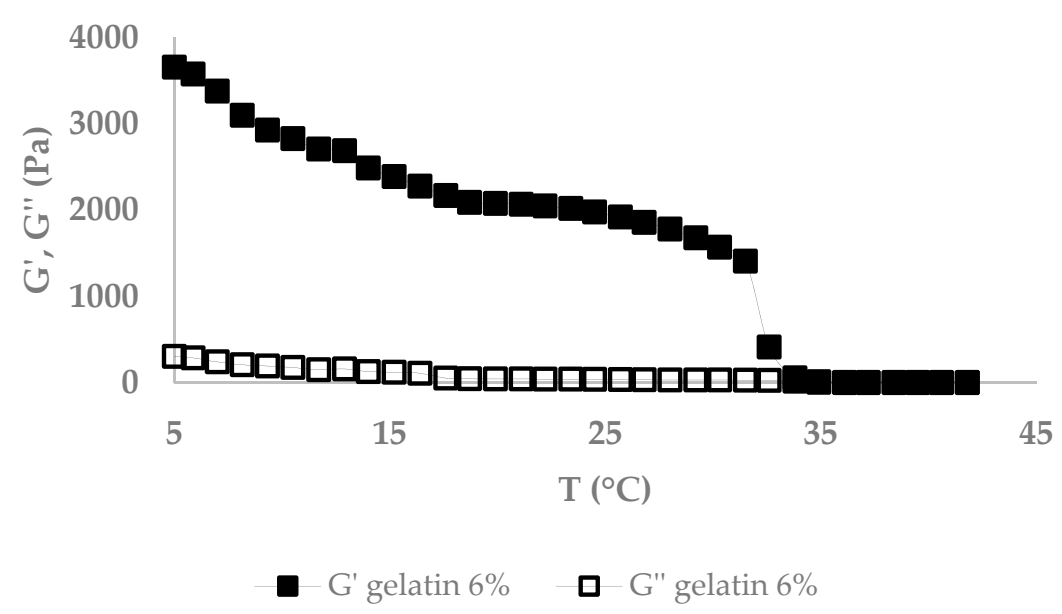

Figure 8. Melting point of gelatin gel (6\%).

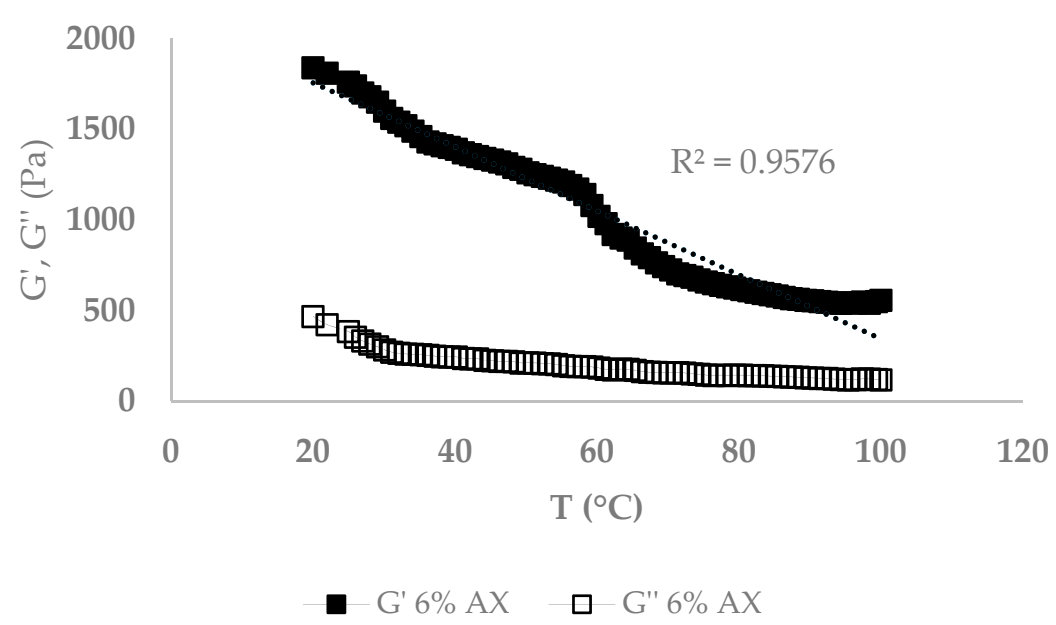

Figure 9. Melting point of arabinoxylan gel (6\%). 


\subsection{Water Holding Capacity}

Water holding capacity is defined as the physical property, which prevents water from being released from the structure of the gel [34]. The water holding capacities for arabinoxylan gels (formed with LccPpu) and gelatin gels were determined to be $98.2 \%$ and $98.6 \%$, respectively.

\subsection{Swelling Ratio}

Figure 10 presents the swelling ratio of gelatin and AX gels (formed with LccPpu). A linear correlation $\left(R^{2}=0.98\right)$ between swelling ratio of the AX gel and immersing time in artificial saliva was recorded.

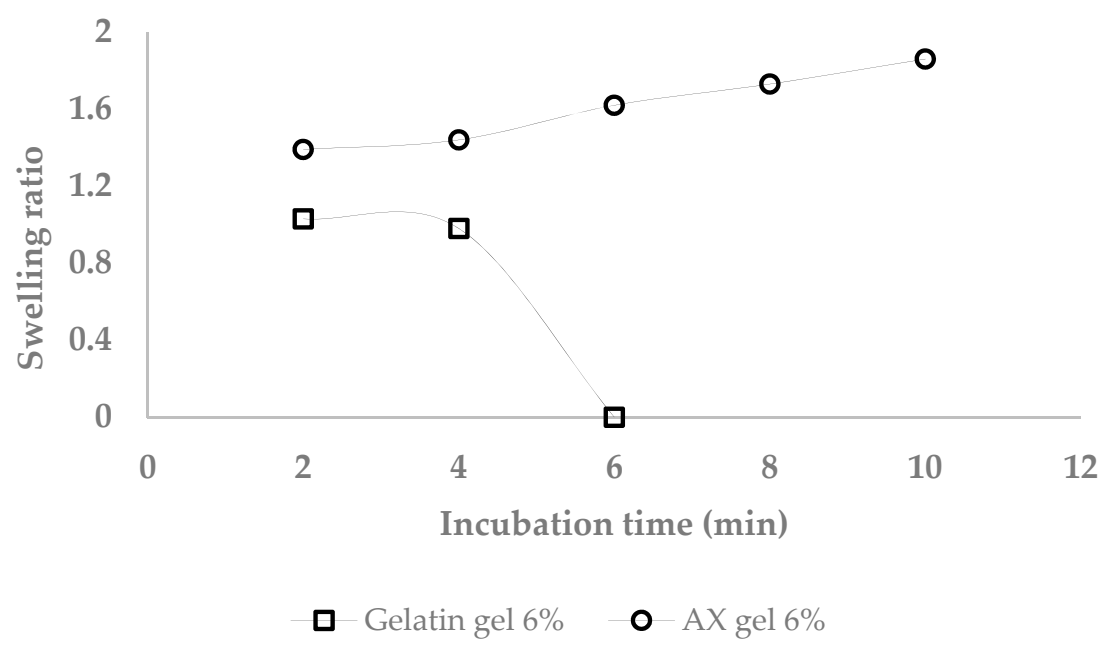

Figure 10. Swelling ratio of gelatin $(6 \%)$ and arabinoxylan gel $(6 \%)$ in artificial saliva at room temperature.

\section{Discussion}

\subsection{Wheat Bran Arabinoxylan}

The most common method of separating arabinoxylan on a large scale is alkaline extraction using sodium hydroxide, potassium hydroxide, or barium hydroxide solutions (1 $\mathrm{M}$ for $16 \mathrm{~h}$ ) [35]. Although alkaline treatment increases arabinoxylan yield, it hydrolyses ferulic acid bonds. In the current study, $\mathrm{AX}$ was treated with sodium hydroxide $0.5 \mathrm{M}$ for $40 \mathrm{~min}$ only. The reduced $\mathrm{pH}$ and shorter treatment time led to a decrease of AX yield from $6 \%$ to $2.8 \%$ (mass of AX/mass of wheat bran), but increased the ferulic acid content from non-detectable to $2.17 \pm 0.06 \mu \mathrm{g}$ ferulic acid $/ \mathrm{mg} \mathrm{AX}$. The self-extracted AX could therefore be used for gel formation, which is not possible with commercially available AX.

\subsection{Wheat Bran Arabinoxylan Gel Characterization}

Arabinoxylan gels have higher storage than loss moduli. This indicates viscoelastic behavior of the gels [36]. The higher loss $\left(G^{\prime \prime}\right)$ than storage modulus $\left(G^{\prime}\right)$ in the negative control was attributed to a lack of ferulic acid moieties. The AX gelation process and gel properties are governed by the establishment of covalent (di-FA, tri-FA bridges) linkages [37]. The more intact ferulic acid moieties on the polysaccharide backbone, the more covalent cross-links may be formed [9]. Carvajal-Millan et al. reported that an elevation in ferulic acid concentration from 0.93 to $1.4 \mu \mathrm{g} / \mathrm{mg}$ led to an increase in storage modulus for $1 \%$ AX gels from 6 to $43 \mathrm{~Pa}$. [9].

According to the results, self-extracted AX with intact ferulic acid moieties formed a firm gel structure as shown by its high storage modulus (Table 1). This was not observed when the same conditions were applied to commercial AX samples (negative control) [38]. 
A loss factor lower than one indicates elastic while higher than one implies viscous properties [39]. The negative control, which contained no ferulic acid, did not form a firm gel, as proven by higher loss factors $(\tan \delta \geq 1)$. In contrast, the self-extracted AX formed a solid gel.

\subsection{Different Laccases from Basidiomycetes}

Laccase $\mathrm{C}$ had $1.9 \mathrm{U} / \mathrm{mg}$ xylanase activity, which may have led to the observed weaker gel network by slowly hydrolyzing glycosidic bonds of the AX main chain (Figure 1) [40]. In contrast, the high purity of the laccases Ppu and Ftr most likely contributed to gels with a firmer structure.

\subsection{Effect of Citrus Pectin and Mediators on Arabinoxylan Gels}

A series of experiments was conducted to enhance the rheological properties of AX gels through mediators (Table 2). Although CA ( $5 \mathrm{mM}$ ) clearly improved the storage modulus of cross-linked yogurt formed with LccC [21], it had a devastating impact on the storage moduli of AX gels. The inhibitory impact of caffeic acid was attributed to its oxidation while reducing the semiquinones of ferulic acid produced by laccases. Therefore, ferulic acid was no longer oxidized to dimers [41].

Increasing the concentration of ABTS to $5 \mathrm{mM}$ was followed by a decrease in the storage modulus of AX gels (Table 2). Higher concentrations of ABTS competed with ferulic acids for laccase. In addition, it was reported that the laccase/ABTS system coupled ABTS to ferulated arabinoxylan, rather than causing dimerization of ferulic acids [32].

Citrus pectin, a common thickening and gelling agent, has the ability to link with various compounds to form a gel [42]. Nonetheless, as shown in Table 2, it did not have a significant impact on the viscoelastic properties of AX gels. Overall, addition of pectin resulted in hydrogen bonds and hydrophobic interactions in the gel, instead of increasing covalently cross-linked bonds [43]. To sum up, the investigated mediators were not successful in improving the rheological properties of cross-linked AX gel.

\subsection{Storage Stability of Arabinoxylan Gels}

Since the aim of the project was to form a hard gel, which was stable during storage, a rheological analysis was performed over six weeks of storage. AX gels formed with Laccase C showed a sudden drop of $G^{\prime}$ after two weeks storage. Xylanase in the enzyme preparation may have started hydrolyzing the AX main chain and broken down the gel structure [44]. Gels formed using laccase Ftr and Ppu were stable for four and six weeks, respectively (Figure 3). In contrast to earlier findings [45], no syneresis was observed in gels over the course of this work. This may be attributed to the three times higher FA concentration of the AX used in the previous work. As a result, the network contracted more easily due to increasing polymer chain connectivity [45]. Some softening of the structure was observed after four weeks of storage. Laccase-produced radicals were probably responsible for this phenomenon. Radicals participating in secondary reactions may have led to a beginning degradation of the AX main chains [46]. It was recently reported that a $90 \mathrm{~min}$ heat treatment at $85^{\circ} \mathrm{C}$ significantly decreased the laccase activity. As a result, the storage modulus of sweetened cross-linked fibrex gels formed with LccFtr stayed stable for over a month of storage after the above-mentioned heat treatment. Due to their highly similar chemical structure, these results should be transferable to the AX gels in this study [47].

\subsection{Viscoelastic Properties of AX and Gelatin Gels}

Cross-linking of AX with LccFtr and LccPpu formed elastic gels with viscoelastic properties comparable to gelatin gels. AX gels, like traditional gelatin gels, do not raise nutritional concerns as Bifidobacterium enzymes present in the human large intestine degrade them [46]. The covalent structure of cross-linked AX gels confers them some superior characteristics, such as high water absorption capacity and stability to $\mathrm{pH}$, temperature, and ionic charges [32]. 


\subsection{Identifying Diferulic Acids in Cross-Linked Arabinoxylan Gel}

AX gels formed with LccPpu were analyzed with LCMS/MS, and 8-O-4' dehydrodimers of ferulic acid were detected as cross-links. Dominating dimers of ferulic acids in cross-linked wheat bran AX were 8-O-4' and 8-5', both of which increased after gel formation [44,47]. It was recently reported that in the cross-linked gels, which were formed with LccFtr, 8-5' dimers of ferulic acids were predominant [47]. The production of dimers of ferulic acids corresponded to the consumption of ester-bound ferulic acid [41]. Obviously, due to different substrate specificities, laccase Ppu formed phenoxy radicals by absorption of the $\mathrm{H}$ atom of the $\mathrm{OH}$ group at the $\mathrm{C}-4$ ring position of ferulic acid, while laccase Ftr preferred the C-5 ring position.

In addition, a big peak at a retention time of about $11 \mathrm{~min}$ with 386.6 and $387.1 \mathrm{~m} / \mathrm{z}$ ions showed a clusteration. The difference of 0.5 amu between the detected masses means that an ion possessing a double charge was present. This is interpreted as a clustered diferulate of as of now unknown structure. Recently, formation of cross-links of ferulic acid of higher molecular masses than dimers and undefined superior structures was reported [32].

\subsection{Arabinoxylan and Gelatin Gel Structural Characteristics}

The melting point, water holding capacity, and swelling ratio were determined to investigate physical properties of the gels. Analyzing the melting point of gelatin gels showed a drop in storage modulus at almost $35^{\circ} \mathrm{C}$, followed by a $\mathrm{G}^{\prime \prime}$ overtaking $\mathrm{G}^{\prime}$ (Figure 8). AX gels gradually decreased in $G^{\prime}$, and $G^{\prime}$ stayed greater than $G^{\prime \prime}$ during the heating process (Figure 9). The higher temperature stability of the AX gel must be attributed to the covalent bonds formed after oxidative coupling of the ferulic acids [32].

The high Water Holding Capacity (WHC) of AX gels, which equaled that of the gelatin gel, resulted from the three-dimensional network that was able to retain a large aqueous phase and provided a structure stable against syneresis and shrinkage [32,45].

Estimated swelling ratio of the AX gel (in water and for $36 \mathrm{~h}$ incubation at room temperature) was higher than theoretically determined from the diferulic acid content of AX gels. It was suggested that in addition to di-FA and tri-FA, higher ferulated cross-linking and physical entanglements would contribute to the final arabinoxylan gel structure [9]. In contrast, the hydrogen bonds of the gelatin gel were dissolved by the penetrating water molecules after five minutes storage at room temperature.

\section{Conclusions}

The present study showed that AX obtained by a modified alkaline extraction method was successfully cross-linked with purified laccases from the basidiomycetes Funalia trogii (LccFtr) and Pleurotus pulmonarius (LccPpu). The new AX gels resembled gelatin gels in terms of storage modulus, loss factor $(\tan \delta<0.5)$, high water holding capacity, and digestibility. The AX gels retained their viscoelastic properties during a storage period of up to six weeks at $25^{\circ} \mathrm{C}$ (LccPpu, Figure 3 ) and may be classified vegan. However, temperature stability and swelling behaviour of the AX and gelatin gels (Figures 8-10) were different and reflected the difference between covalent and hydrogen bond network knots. The thermo-reversible gelatin gels are known as an easy process product, which melt at body temperature. However, they have low stability to heat and are soluble only at higher temperatures [1]. Arabinoxylan gels provide a heat resistant gel, formed at room temperature and as firm as gelatin, which could be applied in pharmaceutical and other industries.

Covalent cross-links were proven by 8-O-4 dimers of ferulic acids as well as clusters of diferulic acids, which will have to be analyzed in more detail after analytical declusteration.

The refined extraction method and the enzymatic cross-linking concept appear promising to provide gels with a firm texture that is stable over an extended period of time. Sensory tests must be performed to investigate the organoleptic properties of the gels including the release of volatile and 
non-volatile ingredients typically contained in a wide range of foods, such as candies, confectionary, liquorice products, glaze, and desserts.

Author Contributions: S.K. and R.G.B. conceived and designed the experiments; S.K. performed the experiments; S.K. analyzed the data; R.G.B. and F.E. contributed materials and analysis tools; S.K. and F.E. wrote the paper. All authors have read and agreed to the published version of the manuscript.

Funding: The publication of this article was funded by the Open Access fund of Leibniz Universität Hannover.

Acknowledgments: The authors are grateful to U. Krings at the Institute of Food Chemistry, LU Hannover, for his skilful mass spectrometric analyses and help with the interpretation of the MS/MS data. We also thank D. Linke for helpful assistance.

Conflicts of Interest: The authors have no affiliation with any organization with a direct or indirect financial interest in the subject matter discussed in the manuscript.

\section{References}

1. Karim, A.; Bhat, R. Gelatin alternatives for the food industry: Recent developments, challenges and prospects. Trends Food Sci. Technol. 2008, 19, 644-656. [CrossRef]

2. Morrison, N.A.; Clark, R.C.; Chen, Y.L.; Talashek, T.; Sworn, G. Gelatin alternatives for the food industry. In Progress in Colloid and Polymer Science; Nishinari, K., Ed.; Physical Chemistry and Industrial Application of Gellan Gum; Springer: Berlin/Heidelberg, Germany, 1999; Volume 114, ISBN 978-3-540-48349-6.

3. Anderson, C.; Simsek, S. Mechanical profiles and topographical properties of films made from alkaline extracted arabinoxylans from wheat bran, maize bran, or dried distillers grain. Food Hydrocoll. 2019, 86, 78-86. [CrossRef]

4. Boz, H. Ferulic acid in cerials-A review. Czech J. Food Sci. 2015, 33, 1-7. [CrossRef]

5. Scalbert, A.; Monties, B.; Lallemand, J.Y.; Guittet, E.; Rolando, C. Ether linkage between phenolic acids and lignin fractions of wheat straw. Phytochemistry 1985, 24, 1359-1362. [CrossRef]

6. Mendis, M.; Simsek, S. Arabinoxylan and human health. Food Hydrocoll. 2014, 42, 239-243. [CrossRef]

7. Fincher, G.B.; Stone, B.A. A water-soluble arabinogalactan peptide from wheat endosperm by fractional precipitation of their acetates. Aust. J. Biol. Sci. 1974, 27, 117-132. [CrossRef]

8. Smith, M.M.; Hartley, R.D. Occurrence and nature of ferulic acid substitution of cell-wall polysaccharides in graminaceous plants. Carbohydr. Res. 1983, 118, 65-80. [CrossRef]

9. Carvajal-Millan, E.; Landillon, V.; Morel, M.H.; Rouau, X.; Doublier, J.L.; Micard, V. Arabinoxylan gels: Impact of the feruloylation degree on their structure and properties. Biomacromolecules 2005, 6, 309-317. [CrossRef] [PubMed]

10. Zhang, X.; Chen, T.; Lim, J.; Gu, F.; Fang, F.; Cheng, L.; Campanella, O.H.; Hamaker, B.R. Acid gelation of soluble laccase-crosslinked corn bran arabinoxylan and possible gel formation mechanism. Food Hydrocoll. 2019, 92, 1-9. [CrossRef]

11. Bergmans, M.E.F.; Beldman, G.; Gruppen, H.; Voragen, A.G.J. Optimisation of the selective extraction of (glucurono) arabinoxylans from wheat bran: Use of barium and calcium hydroxide solution at elevated temperatures. J. Cereal Sci. 1996, 23, 235-245. [CrossRef]

12. Kale, M.S.; Yadav, M.P.; Hicks, K.B.; Hanah, K. Concentration and shear rate dependence of solution viscosity for arabinoxylans from different sources. Food Hydrocoll. 2015, 47, 178-183. [CrossRef]

13. Berlanga-Reyes, C.; Carvajal-Millan, E.; Lizardi-Mendoza, J.; Islas-Rubio, A.R.; Rascón-Chu, A. Enzymatic cross-linking of alkali extracted arabinoxylans: Gel rheological and structural characteristics. Int. J. Mol. Sci. 2011, 12, 5853-5861. [CrossRef] [PubMed]

14. Stavova, E.; Porizka, J.; Stursa, V.; Enev, V.; Divis, P. Extraction of ferulic acid from wheat bran by alkaline hydrolysis. MendelNet 2017, 24, 574-575.

15. Ayala-Soto, F.E.; Serna-Saldivar, S.O.; Welti-Chanes, J. Effect of processing time, temperature and alkali concentration on yield extraction, structure and gelling properties of corn fiber arabinoxylans. Food Hydrocoll. 2016, 60, 21-28. [CrossRef]

16. Martínez-López, A.L.; Carvajal-Millan, E.; Marquez-Escalante, J.; Campa-Mada, A.C.; Rascón-Chu, A.; López-Franco, Y.L.; Lizardi-Mendoza, J. Enzymatic cross-linking of ferulated arabinoxylan: Effect of laccase or peroxidase catalysis on the gel characteristics. Food Sci. Biotechnol. 2019, 28, 311-318. [CrossRef]

17. Baldrian, P. Fungal laccases-occurrence and properties. FEMS Microbiol. Rev. 2006, 30, 215-242. [CrossRef] 
18. Bender, D.; Regner, M.; D'Amico, S.; Jäger, H.; Tömösközi, S.; Schoenlechner, R. Effect of differently extracted arabinoxylan on gluten-free Sourdough-Bread Properties. J. Food Qual. 2018, 2018, 1-10. [CrossRef]

19. Flander, L.; Rouau, X.; Morel, M.H.; Autio, K.; Seppänen-Laakso, T.; Kruus, K.; Buchert, J. Effects of laccase and xylanase on the chemical and rheological properties of oat and wheat doughs. J. Agric. Food Chem. 2008, 56, 5732-5742. [CrossRef]

20. Osma, J.F.; Toca-Herrera, J.L.; Rodríguez-Couto, S. Uses of laccases in the food industry. Enzym. Res. 2010, 2010, 1-8. [CrossRef]

21. Struch, M.; Linke, D.; Mokoonlall, A.; Hinrichs, J.; Berger, R.G. Laccase catalyzed crosslinking of skimmed milk yoghurt enhanced by food-grade mediators. Int. Dairy J. 2015, 49, 89-94. [CrossRef]

22. Cańtizares-Macias, P.; Hernandez-Garciadiego, L.; Gomez-Ruiz, H. An automated flow injection analysis procedure for the determination of reducing sugars by DNSA methods. J. Food Sci. 2006, 66, 407-411. [CrossRef]

23. Behrens, C.; Linke, D.; Allister, A.B.; Zelena, K.; Berger, R.G. Variants of PpuLCC, a multi-dye decolorizing laccase from Pleurotus pulmonarius expressed in Pichia pastoris. Protein Expr. Purif. 2017, 137, 34-42. [CrossRef] [PubMed]

24. Kolwek, J.; Behrens, C.; Linke, D.; Krings, U.; Berger, R.G. Cell-free one-pot conversion of (+)-valencene to (+)-nootkatone by a unique dye-decolorizing peroxidase combined with a laccase from Funalia trogii. J. Ind. Microbiol. Biotechnol. 2018, 45, 89-101. [CrossRef] [PubMed]

25. Francis, F.J. Wiley Encyclopaedia of Food Science and Technology, 2nd ed.; John Wiley \& Sons Inc.: London, UK, 1999; Volume 4, ISBN 978-0-471-19285-5.

26. Nieter, A.; Kelle, S.; Linke, D.; Berger, R.G. Feruloyl esterases from Schizophyllum commune to treat food industry side-streams. Bioresour. Technol. 2016, 220, 38-46. [CrossRef] [PubMed]

27. Schulz, K.; Nieter, A.; Scheu, A.K.; Copa-Patiño, J.L.; Popper, L.; Berger, R.G. A type D ferulic acid esterase from Streptomyces werraensis affects the volume of wheat dough pastries. Appl. Microbiol. Biotechnol. 2018, 102, 1269-1279. [CrossRef]

28. Malunga, L.N.; Beta, T. Isolation and identification of feruloylated arabinoxylan mono-and oligosaccharides from undigested and digested maize and wheat. Heliyon 2016, 2, e00106. [CrossRef]

29. Chen, M.J.; Lin, C.W. Factors affecting the water-holding capacity of fibrinogen/plasma protein gels optimized by response surface methodology. J. Food Sci. 2002, 67, 2579-2582. [CrossRef]

30. Amal, A.; Hussain, S.; Jalaluddin, M. Preparation of artificial saliva formulation. Int. Conf. ICB Pharma II 2015, A002, 6-12.

31. Miller, G.L. Use of dinitrosalicylic acid reagent for determination of reducing sugar. Anal. Chem. 1959, 31, 426-428. [CrossRef]

32. Mendez-Encinas, M.A.; Carvajal-Millan, E.; Rascon-Chu, A.; Astiazaran-Garcia, H.F.; Valencia-Rivera, D.E. Ferulated arabinoxylans and their gels: Functional properties and potential application as antioxidant and anticancer agent. Oxid. Med. Cell. Longev. 2018, 2018, 1-22. [CrossRef]

33. Vismeh, R.; Lu, F.; Shishir, P.S.; Chundawat, S.; Humpula, J.F.; Azarpira, A.; Balan, V.; Dale, B.E.; Ralph, J.; Jones, A.D. Profiling of diferulates (plant cell wall cross-linkers) using ultrahigh-performance liquid chromatography mass spectrometry. Analyst 2013, 138, 6683-6692. [CrossRef] [PubMed]

34. Zayas, J.F. Water holding capacity of proteins. In Functionality of Proteins in Food; Springer: Berlin/Heidelberg, Germany, 1997; ISBN 978-3-642-63856-5.

35. Börjesson, M.; Härdelin, L.; Nylander, F.; Karlsson, K.; Larsson, A.; Westman, G. Arabinoxylan and nanocellulose from a kilogram-scale extraction of barley husk. BioRES 2018, 13, 6201-6220.

36. Barnes, H.A. Chapter 6. In A Handbook of Elementary Rheology; The University of Wales, Institute of Non-Newtonian Fluid Mechanics, Department of Mathematics: Cardiff, UK, 2000; ISBN 92-5-101137-0.

37. Vansteenkiste, E.; Babot, C.; Rouau, X.; Micard, V. Oxidative gelation of feruloylated arabinoxylan as affected by protein. Influence on protein enzymatic hydrolysis. Food Hydrocoll. 2004, 18, 557-564. [CrossRef]

38. Hollmann, J.; Lindhauer, M.G. Pilot-scale isolation of glucuronoarabinoxylans from wheat bran. Carbohydr. Polym. 2005, 59, 225-230. [CrossRef]

39. Eidam, D.; Kulicke, W.M.; Kuhn, K.; Stute, R. Formation of maize starch gels selectively regulated by the addition of hydrocolloids biosynthesis. Starch Starke 1995, 47, 378-384. [CrossRef]

40. Van Den Brink, J.; De Vries, R. Fungal enzyme sets for plant polysaccharide degradation. Appl. Microbiol. Biotechnol. 2011, 91, 1477-1492. [CrossRef] [PubMed] 
41. Figueroa-Espinoza, M.C.; Rouau, X. Effect of cysteinyl caffeic acid, caffeic acid, and L-dopa on the oxidative cross-linking of feruloylated arabinoxylans by a fungal laccase. J. Agric. Food Chem. 1999, 47, 497-503. [CrossRef]

42. Saha, D.; Bhattacharya, S. Hydrocolloids as thickening and gelling agents in food: A critical review. J. Food Sci. Technol. 2010, 47, 587-597. [CrossRef]

43. Gawkowska, D.; Cybulska, J.; Zdunek, A. Structure-related gelling of pectins and linking with other natural compounds: A review. Polymers 2018, 10, 762. [CrossRef]

44. Carvajal-Millan, E.; Guigliarelli, B.; Belle, V.; Rouau, X.; Micard, V. Storage stability of laccase induced arabinoxylan gels. Carbohydr. Polym. 2005, 59, 181-188. [CrossRef]

45. Morales-Burgos, A.M.; Carvajal-Millan, E.; Lopez-Franco, Y.; Rascon-Chu, A.; Lizardi-Mendoza, J.; Sotelo-Cruz, N.; Brown-Bojorquez, F.; Burgara-Estrella, A.; Pedroza-Montero, M. Syneresis in gels of highly ferulated arabinoxylans: Characterization of covalent cross-linking, rheology, and microstructure. Polymers 2017, 9, 164. [CrossRef] [PubMed]

46. Anderson, C.; Simsek, S. What are the characteristics of arabinoxylan gels? Food Nutr. Sci. 2018, 9, 818-833. [CrossRef]

47. Khalighi, S.; Berger, R.G.; Ersoy, F. Cross-linking of fibrex gel by fungal laccase: Gel rheological and structural characteristics. Process 2020, 8, 16. [CrossRef]

(C) 2019 by the authors. Licensee MDPI, Basel, Switzerland. This article is an open access article distributed under the terms and conditions of the Creative Commons Attribution (CC BY) license (http://creativecommons.org/licenses/by/4.0/). 